\title{
Graphene Oxide based Nanocomposite for Crop Protection
}

\author{
Zuzana Bytešníková ${ }^{1,2}$, Jakub Pečenka $^{3}$, Lukáš Richtera ${ }^{1,2}$, Dorota Tekielska ${ }^{3}$, Aleš Eichmeier ${ }^{3}$, Vojtěch \\ Adam 1,2 \\ ${ }^{1}$ Department of Chemistry and Biochemistry \\ Mendel University in Brno, Zemědělská 1, 61300 Brno, Czech Republic \\ zuzana.bytesnikova@mendelu.cz; lukas.richtera@mendelu.cz \\ ${ }^{2}$ Central European Institute of Technology, Brno University of Technology \\ Purkyňova 656/123, 61200 Brno, Czech Republic \\ ${ }^{3}$ Mendeleum - Institute of Genetics, Faculty of Horticulture, Mendel University in Brno \\ Valticka 337, 69144 Lednice, Czech Republic \\ jakub.pecenka@mendelu.cz
}

Keywords: Nanomaterials, Xanthomonas, plant pathogen, crop protection, graphene oxide.

\section{Extended Abstract}

Statistical current world production of tomato and pepper was according Food and agriculture Organisation (FAO) 180 milions tons and 40 milions tons respectively in 2017.

In 2004, bacterial spot-causing xanthomonads (BSX) were reclassified into 4 species-Xanthomonas euvesicatoria, $X$. vesicatoria, X. perforans, and X. gardneri. BSX has ability to cause disease at different temperatures and has broad spectrum of diversity. The facts make the Xanthomonas a worldwide threat to pepper and tomato production and causes serious economic losses. Chemical control of pathogens led to increase of resistance. The current strategy to control BSX disease is based on planting resistant cultivars. Nevertheless, durability of resistance has been fleeting [1]. Treatment of plant by nanomaterials with antibacterial activity can be possible solution.

Graphene oxide (GO) was prepared by chemical oxidation according to the simplified Hummer's method [2, 3]. GO was used as a starting materials for synthesis of nanocompostites consisting of GO and metal NPs. The morphology and elemental analysis of nanocomposites was performed using a scanning electron microscope (SEM) with energy dispersive X-ray spectroscopy (EDS). The interactions between GO and metal NPs were studied using Fourier transform infrared spectroscopy (FT-IR). Antibacterial activity of nanocompostites was tested on Xanthomonas euvesicatoria by plate pour method. Nanocomposites with the best antibacterial activity were tested in vivo study with tomato (cultivar "Mandat") and pepper (cultivar "Citrina") plants. Antibacterial activity of GO and metal NPs itself was tested also and the results were compared with antibacterial activity of composite.

Synthesized nanocomposite was confirmed with SEM. EDS analysis was used to recognition elemental composition of nanocomposite. Comparative FTIR analysis was conducted to detect changes in functional groups. The addition of $\mathrm{Cu}$ and $\mathrm{Ag}$ NPs to the GO resulted in an increase in $\mathrm{C}=\mathrm{C}$ moiety signals in the $1550-1650 \mathrm{~cm}^{-1}$ region. Another increase has occurred in $\mathrm{C}=\mathrm{O}$ signals in the $1700-1800 \mathrm{~cm}^{-1}$ region, $\mathrm{O}-\mathrm{H}$ signals in the $3580-3650 \mathrm{~cm}^{-1}$ region, and $\mathrm{O}-\mathrm{C}$ signals in the $1320 \mathrm{~cm}^{-}$ ${ }^{1}$ region. $\mathrm{Cu}-\mathrm{O}$ showed peak at $600 \mathrm{~cm}^{-1}$, which confirms structure of composite. A composite consisting of GO, copper and silver was selected in vitro for further in vivo testing. The composite exhibited enhanced antibacterial activity than GO or metal NPs itself.

Preliminary results show that the designed nanocomposite consisting of GO with copper and silver NPs display high potential for application in crop protection.

\section{Acknowledgements}

This work was financially supported by ERDF 'Multidisciplinary research to increase application potential of nanomaterials in agricultural practice' (No. CZ.02.1.01/0.0/0.0/16_025/0007314). 


\section{References}

[1] N. Potnis, S. Timilsina, A. Strayer, D. Shantharaj, J. D. Barak, M. L. Paret, G. E. Vallad, J. B. Jones, "Bacterial spot of tomato and pepper: diverse Xanthomonas species with a wide variety of virulence factors posing a worldwide challenge," Molecular Plant Pathology, vol. 16, pp. 907-920, Dec 2015.

[2] W. S. Hummers and R. E. Offeman, "Preparation of Graphitic Oxide," Journal of the American Chemical Society, vol. 80, pp. 1339-1339, 1958.

[3] W. Gao, L. B. Alemany, L. J. Ci, and P. M. Ajayan, "New insights into the structure and reduction of graphite oxide," Nature Chemistry, vol. 1, pp. 403-408, Aug 2009. 